\title{
Information and command infrastructures for small and medium size enterprises
}

\author{
J. Goossenaerts ${ }^{a}$, A.P. Azcarraga ${ }^{b}$, C.M. Acebedo ${ }^{c}$ and D. Bjørner ${ }^{a}$ \\ ${ }^{a}$ United Nations University, International Institute of Software Technology \\ P.O. Box 3058, Macau \\ ${ }^{b}$ College of Computer Studies, De La Salle University \\ 2401 Taft Avenue, 1004 Manila, Philippines \\ ${ }^{c}$ Industrial Engineering Department, De La Salle University \\ 2401 Taft Avenue, 1004 Manila, Philippines
}

\begin{abstract}
The scope of the problem of designing an information and command infrastructure for Small and Medium Size manufacturing enterprises is explained. The rôle of enterprise and industry modelling during the infrastructure design phase and the rôle of model execution services are summarized. An outline of the $\mathrm{Ml}^{2} \mathrm{Cl}$ Philippines project shows an approach to demonstrating and disseminating integrated enterprise and industry modelling know how in support of the operations and projects of SMEs.
\end{abstract}

\section{Keywords}

Infrastructure, enterprise and environment modelling, model execution services, small and medium size enterprises

\section{INTRODUCTION}

Traditionally, the term infrastructure is used in reference to services in the areas of sanitation, water, power, transportation, irrigation, roads and telecom. Because infrastructure services raise productivity and lower production costs they form an important component in development policies (The World Bank, 1994).

The term manufacturing industry information and command infrastructure (abbreviated: $M I^{2} \mathrm{Cl}$ ) is proposed in reference to an information processing and activity control and monitoring system which provides information and control services in support of the operations and projects of manufacturing enterprises. Actors that are anticipated to involve in the design and exploitation of $\mathrm{MI}^{2} \mathrm{Cl}$ services include public-sector industry support organisations, chambers of commerce, trade associations, industry research and development centers, information and communications technology suppliers, telecom network operators and enterprises. 
The important rôle of small businesses as instruments of job creation and product and service innovation justifies initiatives to set up information and command infrastructures for them. Meeting the requirements of small businesses requires one to address key issues such as the identification of services and exploitation concepts adapted to SME's needs, the inter-operability of services, access and ease of use, information protection and confidentiality. Addressing this amalgam of issues while avoiding the creation of an amalgam of overlapping and incompatible solutions requires one to construct a global and integrated picture of the problem area prior to the implementation of the infrastructure services. Systematized information about products, business and manufacturing processes, markets, technologies, and regulations is needed.

The concepts of genericity and model life cycle proposed in the European Prestandard ENV 400.03 (1990) are indispensable in systematizing information for industries prior to the design, implementation and particularization of infrastructure services. The second chapter of this paper proposes three more organizing principles. The life cycle principle: the life cycles of products and plants are the prime phenomena-flow based and unavoidable life cycles to engineer, manage and realize. The interflow principle: by articulating the interfaces between executing models on the one hand and physical operations and/or projects on shop floor and in engineering offices on the other hand, one can more easily cope with the balance between human work, automation and information technology. The decomposition principle: decomposing a manufacturing industry into the generic orthogonal systems plant, team, market and industry allows one to target services and reduce system complexity. After their introduction, the principles are linked to enterprise and industry modelling during the infrastructure design phase, and to the design and execution services.

The $\mathrm{MI}^{2} \mathrm{Cl}$ Philippines Project is the first project in which we try to validate the use of integrated enterprise and industry modelling know how in support of industrial development. It is a joint project of De La Salle University, UNU/IIST and the United Nations Industrial Development Organization (UNIDO). The project assumes that SMEs, to respond to opportunities and changes, and to establish dynamic value-creating partnerships in extended enterprises (Browne et al., 1994), need to deploy advanced information technology within enterprises as well as in the business environment. However, it is also recognized that high degrees of automation are rarely compatible with the socio-economic situation in developing countries, including the high level of unemployment, low investment and poor bankability of SMEs, and the lack of human resources. Therefore, to achieve the target of a balanced deployment of human work, automation and information technology in SMEs, it is necessary for the $\mathrm{MI}^{2} \mathrm{Cl}$ project to take up two work packages: a requirements analysis and an applicability study. The requirements analysis of the metal works industry in the Philippines will guide the formulation of a Philippine Business Environment Model and help to formulate an exploitation concept for $\mathrm{MI}^{2} \mathrm{Cl}$ services. The applicability study will focus primarily on: (a) the particularization of partial and particular enterprise and industry models from the generic model described by Goossenaerts \& Bjørner (1994); (b) the implementation of execution services for such models ; and (c) the implementation of prototype systems for shop floor control and for supply chain operations.

\section{PRINCIPLES FOR ORGANIZING MANUFACTURING REQUIREMENTS}

\section{The Interflow Orientation}

Manufacturing industry and enterprises can be considered as interflow systems in which distributed information processing systems (computers and humans) synchronize denoted computational flow with phenomena flow on shop floors and in engineering offices.

The concept of interflow articulates the distinction between computations and physical ac- 
tivities. It builds on concepts in modelling and simulation. The interflows relation between computational flows - executed by a network of information processing entitities - and phenomena flows - on shop floor and in the engineering office - requires interface channels for flow synchronization. The three relations (denoted by the symbols $\models$ (models),$I \equiv$ (simulates), and $\aleph \vDash$ (interflows)) matter for successive steps in the construction of enterprises and industries.

\section{The Life Cycle Orientation}

The problem scope for which information and command infrastructures are proposed is - in a bottom-up manner - determined by the life cycles of products and plants. These are the primary - phenomena flow based and unavoidable - cycles to manage, engineer and realize.

(1) The life cycle of a plant is concerned with: (a) Projects which phase a plant and its products into a market: the gradual introduction of a new plant and its products into a market (and environment). (b) Operations: a plant will respond to orders issued by customers, by exploding the orders into plant programme steps, by scheduling and carrying out the (production) steps, and by delivering the goods ordered. Projects during operations may concern: (i) How to phase in\&out products, equipment and human resources into a plant. (ii) How to improve plant operations. (c) Projects which phase out a plant and its products: the gradual withdrawal from use of an old plant and its old products.

(2) The life cycle of a product is concerned with: (a) Its creation in a (virtual) plant system. (b) Its usage by consumers on the market. Usage of the product may include maintenance, repair, upgrading, etc. (c) Its decomposition - preferably with recycling or reuse of its composing materials - in a (virtual) plant system.

\section{The Orthogonal Systems of Manufacturing Industry}

The focus on (collaborative) labour in the product and plant life cycles and the requirement of orthogonality for the systems to describe these suggest: First, to make, in an enterprise, a distinction between "repetitive" operations, to be catered for in a plant model; and "one-of-akind" improvements and innovations to be catered for in projects carried out by teams; Secondly, when extending the viewpoint beyond the boundary of the enterprise to let extended-enterprise operations be carried out by so-called virtual plants, and to let extended-enterprise projects be carried out by virtual teams. A virtual enterprise (or extended enterprise (Browne et al., 1994)) comprises a virtual team and a virtual plant; And thirdly, to consider markets as the contexts within which enterprises are embedded, and to use the term industry to denote this context when considering the projects and virtual projects executed in the market (e.g. industrial policy projects).

The following domains (Table 1) are proposed to organize the objects, processes and issues in industry (see also Goossenaerts \& Bjørner (1994)) : (a) A team phases in and out a plant or a product in response to goals formulated by entrepreneurs or other agents of change. A team refines and enriches the goals into project programmes for changing or making a (virtual) plant, it schedules and carries out these programmes, finally, it delivers the new or improved plant, capable of producing goods, with the performance expressed in the goals. (b) A plant responds to orders issued by customers, by exploding the orders into plant programme steps, by scheduling and carrying out the (production) steps, and by delivering the goods ordered. (c) A virtual plant comprises several plant systems which synchronize their operations as if they were carried out by a single plant. (d) A virtual team comprises several teams which synchronize their engineering work and decisions as if they would carry them out as a team within a single enterprise. (e) A market forms the context for the operations of plant systems and virtual plant 
systems. Market regulations (e.g. such as in Company Law and Tax Law) may affect the operations of plant systems and virtual plant systems. (f) An industry forms the context for the projects of (virtual) team systems. Regulations (e.g. such as in Environmental Law, Technical Regulations and international standards) may affect projects.

Table 1 Domains for organizing objects, processes and issues in industry

\begin{tabular}{|l||l|l|}
\hline $\begin{array}{l}\text { activities } \\
\text { context }\end{array}$ & operations & projects \\
\hline \hline enterprise & "one-of-a-kind" \\
extended enterprise & plant / production & team / projects \\
environment & martual plant & virtual team \\
\hline \hline desirable condition & leanness & industry / (policy) innovation \\
\hline
\end{tabular}

The desirable conditions of operations (leanness) and projects (agility) must be realized in different contexts: in the enterprise, in the extended enterprise and in the environment as a whole.

Projects are further classified as follows: (a) Entrepreneurial Projects deal with changes of enterprise level programmes during the enterprise life cycle (e.g. the introduction of new products, business process reengineering, investment appraisal). (b) Engineering Projects are concerned with product life cycle and production processes for the product. Usually they require innovation. (c) Quality Improvement Projects are concerned with product and production process improvements. (d) Industrial Policy Projects pertain to the industrial environment as a whole. Virtual plants result from the successful implementation of projects by virtual teams. These require an explicit attention for inter-organisational engineering - in the extended enterprise - and the (standardized) technology infrastructure it requires.

\section{INTEGRATING REQUIREMENTS IN REFERENCE MODELS}

The use of enterprise models and reference models as tools for organizing and integrating information about enterprise processes is well established. See for instance ENV 40.003 (1990), Scheer (1989), CIMOSA (1993), Spur et al. (1994). Goossenaerts \& Bjørner (1994) introduce also the concept of industry model. A breakthrough in enterprise modelling for SME depends on progress in industry modelling: many commonalities between (partial) enterprise models for SME have their origin in the market rules (the confluence between enterprise operations and market behavioural rules). The relative weaknesses of SMEs in acquiring know how, capital, technology and human resources justify industrial policy projects for boosting their development. But due to the large number and diverse activities of SMEs it is common that such projects target a market or sector rather than specific firms.

As to the use of models - and advanced computer-based tools-in support of the operations and projects of SMEs it is important to consider the particular reality of SMEs, in determining the kind of activities that should be supported (Bonfatti et al., 1994), and in determining the approaches to investments (Tucker et al., 1994). The ESPRIT RUMS Project (Bonfatti et al., 1994) aims at supporting the following activities: (a) verification and assessment of the current manufacturing organisation; (b) evaluation of technological enhancement hypotheses concerning production resources; (c) definition of realistic manufacturing and purchasing budgets holding uncertainty of forecasts in due consideration; (d) production planning with respect to different time horizons on the basis of a unified model of product and process ; and (e) education and 
training of human resources involved in the manufacturing process.

\section{Enterprise Modelling and Industry Modelling in the $\mathrm{MI}^{2} \mathrm{Cl}$ Project}

In the $\mathrm{MI}^{2} \mathrm{Cl}$ Philippines Project aspects to be captured in enterprise models and in the business environment or industry model are as follows:

- The partial and particular enterprise models of the metal work industries should capture internal technological, administrative and human resource facets and the processes involving them. Internal technological facets are related to engineering design, product engineering design, manufacturing engineering design ( $\mathrm{CAD}, \mathrm{CAE})$, process planning, materials and parts processing (CAM, CIM), quality assurance, waste avoidance. Internal administrative facets include procurement, inventory, order processing, customer service processing, personnel, budgets, accounts, and cashier. Internal human resource facets include organisation, division of labor, team work, training, quality assurance, etc.

- A Philippine Business Environment Model should capture external technological, environmental, regulatory, and resource facets and the services and processes involving them. External technological facets include supplier profiles, tool profiles, transportation nets, sub-contracting, standardization, innovation \& technology transfer. Environmental aspects include pollution, environmental impact, material cost. Legal rules and regulations concern reporting obligations, taxes, labour laws, industry association, standardization, quality assurance \& product certification, etc. Financial services include stockholders, venture capital banks, government loan agencies, commercial banks, insurance. External human resource facets include workforce profiles (available skills, wages, \&c.), training opportunities, professional associations.

\section{Enterprise Modelling}

For organizing objects and issues we refer to the orthogonal decomposition. The distinction in the enterprise between repetitive operations and one-of-a-kind projects allows one to split the enterprise models into two components: a plant (interflow) model and a team (interflow) model. These models are related to each other and to phenomena flow. Projects, supported by the team model in execution, transform the plant model and the physical plant. Operations, controlled and supported by the plant model in execution, transform material inputs and produce the products.

Enterprise modelling is concerned with the construction of generic, partial or particular (as defined in ENV 400.03 (1990)) plant interflow models or team interflow models.

\section{The Construction of a Generic Plant Interflow Model.}

A construction of a generic plant interflow model is summarized in Table 2. The first three steps deal with statical structural properties of plant systems. The fourth step allows one to define computational flows over instances of the templates (cf. types) in a plant structure. Configurations of such instances can simulate plant operations. The fifth step deals with the interfaces between a plant system and plant operations. Some remarks to justify the focus of the five steps in the construction: (1) Materials and the work to transform them are described statically by means of part templates describing units of material and work templates describing units of change to material. A Part-Work Structure integrates the information in a bill of materials and in process charts and describes the parts and works required for making products. (2) Cells and the orders they send and receive incorporate the division of labour and the coordination of results. Cell Templates describe cell(s), a cell is a unit capable of sustaining activities/work. Cf. resource model. Order Templates describe orders. An order is sent by one cell to another to request the delivery of a part. A Cell-Order Structure integrates the properties described in 
organization charts and in information flow charts. It is concerned with the division of labour and coordination of results. (3) A Plant Structure results from joining a part-work structure and a cell-order structure. It integrates the statical properties of a plant. (4) Plant System. Instances of cell templates and their responses to order instances can simulate the operations at a shop floor. The term pulse denotes the response by a cell instance to an order instance it receives. Cf. the order handling process. The term flow denotes the integration of pulses. A plant system controlled by a model execution system and interfaced to a suitable discrete event generator, can simulate shop floor operations. (5) Plant Interflow Model. Channel templates describing interface channels are added to the plant system. Interface channels are used to interface a (executed) plant system to a shop floor. They support synchronization through the input and output of particular tasks and signals.

Table 2 The bottom-up construction of a Plant Interflow Model

\begin{tabular}{|c|c|c|c|c|c|c|}
\hline 1 & Part-Work Structure & emplate & $\vDash$ & part(s), Work Template & $F$ & work $(\mathrm{s}))$ \\
\hline 2 & Cell-Order Structure & Template & $\vDash$ & cell(s), Order Template & $\vDash$ & order(s)) \\
\hline 3 & Plant Structure $\vDash \models$ plant(s) & & & & & \\
\hline 4 & Plant System $l \vDash$ plant operations $($ Pulse $l \vDash$ & response & e & order instance, Flow $\iota$ F & & perations) \\
\hline 5 & $\begin{array}{l}\text { Plant Interflow Model } \aleph \vDash \text { plant operations } \\
\text { Plant Interflow System, sync(hronize) cycle }\end{array}$ & & $h 0$ & annel Template $\models$ interf & face & hannel) \\
\hline
\end{tabular}

Team Interflow Models

A team working in an (virtual) enterprise aims for improvements or innovations in a (virtual) plant interflow system. In pursuit of a goal - the sequence of activities towards its accomplishment has not been secured yet - a team will first - during the design\&drafting phase - transform or particularize a plant interflow model (templates, plant structure and plant system consolidate the deliverables during this phase) and next - during the construction phase - construct or upgrade the plant interflow system, by transforming the phenomena flow. In the course of a project, the composition of the team may change: it is adapting it according to changing project activities. In contrast, the cell structure of a traditional plant remains static during operations.

Team interflow models in execution support team activities. A generic team interflow model forms a basis for the implementation of an Integrated Project Support Environment.

\section{Industry Modelling}

The contemporary market is governed by a large and changing collection of regulations and constraints for the operations of plants, producers and consumers. Coping with the regulations and their changes requires high costs, especially for SMEs. Therefore the SMEs are expected to benefit significantly from more integrated and harmonized industry models, the corresponding market-wide information and command infrastructures, and proper model-driven interfaces between their enterprise infrastructure and the industry infrastructure.

Industry Modelling is concerned with the construction of generic, partial or particular market interflow models or industry interflow models. Such models enhance the understanding, coordination and harmonization of rules and other market information.

\section{A Generic Market Interflow Model}

The construction of a generic market (interflow) model parallels the construction of a generic plant (interflow) model. A significant difference is that the cell-order structure is replaced by a person-contract structure. Cells (in plants) communicate with each other in a master-slave 
relation, client-to-server, whereas legal persons (persons, companies and public bodies) in a market communicate (also) as equals, peer-to-peer. Contracts commit two or more legal persons to carry out, during a certain period, a number of exchanges of products or services (including labour, money, etc.). They may express terms of synchronization, obligations, etc., e.g. to incorporate a company a suitable "legal person template" must be selected, this will determine reporting obligations, and - to some extent - the contracts the company can enter into. The legal personality and contracts may also be correlated with the products/services which the enterprise can provide on the market (e.g. banks must be registered in a special commission).

Templates of all legal persons and contracts that exist in a market are joined in a personcontract structure. This structure includes person templates for the public bodies that - because of statutory regulations - are involved in the registration and monitoring of (certain) contracts and exchanges. It also includes contract templates such as for incorporation contracts, labour contracts (between citizens and companies), etc. (Goossenaerts \& Bjørner, 1994).

\section{Industry Interflow Models}

Industry-wide projects such as industrial policy and legislative projects aim at transformations of a market system or sector as a whole. Such transformations may be planned (or designed) in terms of particular market interflow models, prior to their implementation.

Our approach suggests to consolidate the deliverables of industry-wide projects as product, exchange, person and contract templates, (in a) market structure, (in a) market system, (in a) particular market interflow model, and eventually, as (in a) market interflow system.

\section{INFORMATION AND COMMAND INFRASTRUCTURE SERVICES}

The provision of information and command infrastructure services requires (computer network supported) enterprise model execution services. See CEN/TC310/WG1 (1994a) for a statement of requirements for such services and CEN/TC310/WG1 (1994b) for an evaluation of some related initiatives. As to design services, relevant requirements can be sourced from the literature on computer aided design and project support environments.

In the $\mathrm{MI}^{2} \mathrm{Cl}$ Project, subsystems of an information and command infrastructure for enterprises and industry are classified in accordance with the domain decomposition in Table 1 (IMES stands for Interflow Model Execution Services and ISDACS stands for Interflow System Design and Construction Services).

An enterprise information and command infrastructure comprises:

Plant IMES: a plant component which supports the repetitive operations of the enterprise (cf. enterprise wide information systems built around enterprise-wide data models (Scheer, 1989)). Plant ISDACS: a team component which supports the innovations and improvements which the enterprise needs to compete in the market; application packages in a Plant ISDACS may include an entrepreneuring project coach, an engineering project coach and a quality project coach.

An industry information and command infrastructure comprises:

Market IMES: a market component which supports the repetitive operations at the market; application packages in a Market IMES may include material flow monitors, employment monitors, (value added) tax collection systems, trade and transportation systems, an intellectual property monitor, etc.

Market ISDACS: an industry (team) component which supports the one-of-a-kind (industrial policy) innovations and improvements which the industry needs to sustain its competitiveness in the global market; application packages in a Market ISDACS may include an industrial policy project coach. 


\section{CONCLUSIONS AND FUTURE WORK}

The problem domain understanding underlying strategic information and manufacturing technology projects in industrialised countries in combination with achievements in model oriented software development, indicate how we can build information technology applications that may help developing countries to leap forward into the age of sustainable lean/agile supply-based industries. This paper has introduced the concept of information and command infrastructures for SMEs and has explained a framework that can guide the planning of the detailed design and implementation of such infrastructures.

The $\mathrm{MI}^{2} \mathrm{Cl}$ Philippines Project will enable us to further test the conceptual and practical validity of the proposed approach. Work in the near future should focus on: (a) the derivation of particular models from generic ones; (b) the elaboration of generic models for markets, teams and industries; (c) the implementation of the generic models; (d) software tool support for the derivation, interfacing, validation, execution and evaluation of particular models; and (e) software tool support for the specification and implementation of interflow models capable of interflowing with enterprise and industry dynamics.

\section{REFERENCES}

Bonfatti, F., Monari, P.D. and Paganelli, P. (1994) Modelling process by rules: Regularities, alternatives and constraints. In: Vernadat, F., editor, Proceedings of the European Workshop on Integrated Manufacturing Systems Engineering (IMSE'94), INRIA, Grenoble, France, 1994.

Browne, J., Sackett, P. and Wortmann, H. (1994) Industry requirements and associated research issues in the Extended Enterprise. In: Vernadat, F., editor, Proceedings of the European Workshop on Integrated Manufacturing Systems Engineering (IMSE'94), INRIA, Grenoble, France, 1994.

CEN/TC310/WG1 (1994a) CIM systems architecture - enterprise model execution and integration services - statement of requirements. CR1832, CEN/CENELEC, Brussels, Belgium.

CEN/TC310/WG1(1994b) CIM systems architecture - enterprise model execution and integration services - evaluation report. CR1831, CEN/CENELEC, Brussels, Belgium.

CIMOSA (1993) ESPRIT Consortium AMICE, editor. CIMOSA: Open System Architecture for CIM. Springer Verlag, Berlin, 2nd, rev. and ext. edition, 1993.

ENV 40003 (1990) ENV 40 003: Computer integrated manufacturing - systems architecture framework for enterprise modelling. European prestandard, CEN/CENELEC, Brussels.

Goossenaerts, J. and Bjørner, D. (1994) Generic models for manufacturing industry. Technical report no. 32, UNU/IIST, Macau, December 1994.

Scheer, A.-W. (1989). Enterprise-Wide Data Modelling - Information Systems in Industry. Springer-Verlag, Berlin - Heidelberg.

Spur, G., Mertins, K. and Jochem, R. (1994). Integrated Enterprise Modelling. Beuth Verlag, Berlin.

Tucker, D.E., Wainwright, C.E.R. and Thethi, A.J.S. (1994) Integrating manufacturing information systems within small and medium enterprises. In: Vernadat,F., editor,Proceedings of the European Workshop on Integrated Manufacturing Systems Engineering (IMSE'94), INRIA, Grenoble, France.

The World Bank (1994) World Development Report 1994. Oxford University Press,Oxford,UK. 